\title{
Study Notes in Electrical Science
}

Noel M. Morris

Principal Lecturer,

North Staffordshire Polytechnic

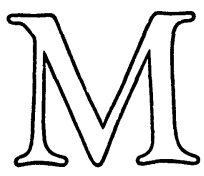


All rights reserved. No part of this publication may be reproduced or transmitted, in any form or by any means, without permission.

First published 1977 by

THE MACMILLAN PRESS LTD

London and Basingstoke Associated companies in New York Dublin

Melbourne Johannesburg and Madras

ISBN 978-0-333-21216-5 ISBN 978-1-349-03123-8 (eBook)

DOI 10.1007/978-1-349-03123-8

Type set in Times New Roman

This book is sold subject to the standard conditions of the Net Book Agreement.

The paperback edition of this book is sold subject to the condition that it shall not, by way of trade or otherwise, be lent, re-sold, hired out, or otherwise circulated without the publisher's prior consent in any form of binding or cover other than that in which it is published and without a similar condition including this condition being imposed on the subsequent purchaser. 


\section{Contents}

Preface vii

Useful Examination Tips viii

Quantities, Multiples and Physical Constants ix

basic SI units-multiples and submultiples of 10-useful physical constants-logarithms-some constants and useful relationships

\section{Direct-current Circuits}

1.1 Basic Electrical Quantities current-quantity - potential - resistance - energy - power

1.2 Ohm's Law derived relationships

1.3 Electrochemical Equivalent

1.4 Thermal Energy 3

1.5 Resistivity and Resistors 3 resistivity-resistors in series and parallel-resistance colour code

1.6 Conductance and Conductivity

conductance — conductivity—conductances in parallel and series

1.7 The Decibel

determination $-\mathrm{dBm}-3 \mathrm{~dB}$

1.8 Circuit Theorems

Kirchhoff's laws-superposition, Thévenin's, Norton's and maximum power-transfer theorems

\section{Electromagnetism}

2.1 Magnetic Field, Magnetic Flux and Flux Density

2.2 Laws of Electromagnetic Induction

Faraday's, Neumann's and Lenz's laws 
2.3 Induced E.M.F.

e.m.f. induced in a coil - induced e.m.f. due to the motion

of a conductor in a magnetic field-Fleming's right-hand rule

2.4 Force on a Conductor

force on a current-carrying conductor in a magnetic fieldscrew rule-Fleming's left-hand rule

2.5 Magnetic Circuits

hysteresis and eddy-current losses-magnetomotive force-magnetic-field strength — magnetic leakage-permeability-reluctance-reluctances in series and parallel

2.6 Magnetisation Curve and Hysteresis Loop magnetisation curve-hysteresis loop

2.7 Inductance

self and mutual inductances-series-connected magnetically coupled circuits-coefficient of mutual inductanceenergy stored in a magnetic field

2.8 Transients in Inductive Circuits

basic circuit - growth and decay of currents

\section{Electrostatics}

3.1 Electric Flux and Flux Density

3.2 Capacitance and Capacitor Current

3.3 Electric Force, Electric-field Intensity or Electric-field Strength

3.4 Permittivity 25

3.5 Capacitance of Parallel-plate Capacitors 26

3.6 Parallel-connected Capacitors $\quad 27$

$\begin{array}{lll}3.7 & \text { Series-connected Capacitors } & 27\end{array}$

3.8 Voltage Distribution between Series-connected Capacitors 28

3.9 Parallel-plate Capacitors with Composite Dielectrics 28

3.10 Energy Stored in a Capacitor $\quad 29$

3.11 Charge and Discharge of a Capacitor 30

basic circuit-capacitor charging and discharging

\section{Alternating-current Theory}

4.1 Basic Concepts

sinusoidal waveform, amplitude and 'angle of rotation'frequency - angular frequency-periodic time

4.2 Average Value and R.M.S. Value of an Alternating

Waveform

average and r.m.s. values-form and peak factors 
4.3 Phasors and Phase Relationships

phasors - phase displacement - addition and subtraction of phasors

4.4 Complex Notation

operator j-rectangular and polar components-complex conjugate-operations with complex quantities

5 Single-phase A.C. Circuits

5.1 Basic Circuits

circuit containing $R$ only-reactance-circuit containing $L$ only-circuit containing $C$ only

5.2 Series Circuits

power factor $-R$ and $L$ in series $-R$ and $C$ in series $-R, L$ and $C$ in series - series resonance

5.3 Parallel Circuits circuit containing $R, L$ and $C$-parallel resonance

5.4 Complex Impedances

reactance-impedance of series and parallel circuits

6 Three-phase A.C. Circuits

6.1 Star-connected Systems voltage and current relationships

6.2 Mesh-connected or Delta-connected Systems current and voltage relationships - power consumed in a balanced load

7 Transformers

7.1 E.M.F. Equation

7.2 Basic Relationships in an Ideal Transformer

7.3 Transformer Efficiency

copper and iron losses - condition for maximum efficiency

7.4 Phasor Diagrams ideal and practical transformers with and without load

7.5 The Transformer as an Impedance-matching Device

\section{Electrical Machines}

8.1 Types of Electrical Machine salient and cylindrical magnetic systems

8.2 Single-excited Machines

8.3 Double-excited Machines

8.4 Windings 
8.5 D.C. Machines

e.m.f. equation - methods of connection

8.6 Characteristic Curves of D.C. Generators separately excited, shunt-excited, series-excited and compound-wound generators

8.7 Power Required to Drive a D.C. Generator

8.8 D.C. Motors torque equation - face-plate starter

8.9 Characteristic Curves of D.C. Motors

shunt, series and compound-wound motors

8.10 Induction Motors

principle - synchronous speed of the magnetic field fractional slip

8.11 Efficiency of Electrical Machines

9 Measurements

9.1 Analog and Digital Instruments

9.2 Effects Utilised in Measuring Instruments 78

9.3 Analog Indicating Instruments 78 controlling and damping forces - methods of supporting moving systems - instrument scales

9.4 Moving-coil Instruments or Galvanometers construction and uses - extending the current and voltage ranges - the moving-coil instrument as an ohmmeter rectifier instruments

9.5 Moving-iron Instruments construction and use - ammeters - voltmeters

9.6 Electrodynamic Instruments

9.7 The D.C. Potentiometer 88

9.8 The Wheatstone Bridge $\quad 88$

9.9 A.C. Bridges $\quad 89$ basic four-arm bridge - De Sauty's, Schering's, Maxwell's and Hay's bridges

9.10 The Cathode Ray Oscilloscope electron gun - electron lens system - deflection system c.r.t. screen - principal controls

10 Rectifiers

10.1 Semiconductors $i$-type - $n$-type - $p$-type

10.2 Rectifiers diode characteristics $-p-n$ junction, Zener and thermionic diodes 
10.3 Rectifier Circuits

single-phase half-wave, full-wave and bridge circuits smoothing circuit

11 Transistors, Triodes and Amplifiers

11.1 Bipolar Junction Transistors

construction - basic configurations - common-emitter and common-base characteristics

11.2 Field-effect Transistors

junction-gate and insulated-gate FETs

11.3 Triodes

11.4 Amplifiers

classification - small-signal amplifiers with bipolar transistors - load line - small-signal common-cathode triode amplifier

11.5 Electronic-device Parameters and Equivalent Circuits use of parameters - hybrid parameters - equivalent circuits

\section{Preface}

This book is a collection of notes and essential diagrams for the study of the subjects of electrical science and electrical principles in T.E.C. courses, City and Guilds of London Institute courses, O.N.C. and O.N.D. courses, and sciencebased O-level and A-level subjects. The treatment is abbreviated and is produced in the most economical form possible.

Present-day syllabuses place an immense burden on students, who have also to deal with advances in technology. This book provides the reader with a summary of the work in electrical science and principles, allowing him to streamline the activities that lead to his final goal.

I should like to express my gratitude to my wife for the assistance she has given during the preparation of this book. Thanks are also due to the Macmillan production and editorial staff for their guidance and help during the production of the book. 


\section{Useful Examination Tips}

1. Find out, at the earliest moment, the time and place of the examination. Start revision well before the examination date (it is often helpful to work out a revision 'timetable', on which you can indicate the days when you intend to deal with each subject area).

2. If you wish to use a portable electronic hand-held calculator, check that the examination regulations permit its use. Remember - an electronic calculator can sometimes provide wrong results more quickly than any other known method! Take a slide rule into the examination with you in case the calculator develops a fault.

3. Be in the examination room at least ten minutes before the start of the examination; this allows time to fill in particulars on the answer paper.

4. Take pencils, drawing instruments, pens, etc., into the examination room with you. A tube of your favourite mints or barley sugar can provide refreshment and aid concentration.

5. Spend several minutes reading through the examination paper before starting your solutions. Make sure that you understand the type of solution required. Mark on the question paper the problems you are going to attempt, and also the order in which you will attempt them.

6. Estimate the time allowed for each question or, alternatively, estimate the time required to obtain each 'mark'. Do not spend an excessive time on sections you prefer to answer at the expense of topics you find more difficult.

7. Clearly number each question in the answer book as you begin it.

8. If you are unable to complete a question, leave sufficient space at the end of it in case you wish to add to it later.

9. Make your drawings large enough to show all necessary detail.

10. If you complete your solutions before the allotted time has elapsed, carefully check your solutions before leaving the room. 


\section{Quantities, Multiples and Physical Constants}

Basic SI units

\begin{tabular}{lrrrr}
\hline Quantity & Symbol & & Unit & Unit symbol \\
\cline { 1 - 2 } length & $l, L$ & & metre & $\mathrm{m}$ \\
mass & $m$ & & kilogram & $\mathrm{kg}$ \\
time & $t$ & & second & $\mathrm{s}$ \\
current & $I$ & & ampere & $\mathrm{A}$ \\
absolute temperature & $T$ & & kelvin & $\mathrm{K}$ \\
luminous intensity & $I$ & & candela & $\mathrm{cd}$ \\
plane angle & $\alpha, \beta, \theta$ & & radian & $\mathrm{rad}$ \\
solid angle & $\Omega, \omega$ & & steradian & $\mathrm{sr}$ \\
\hline
\end{tabular}

Multiples and submultiples of 10

\begin{tabular}{lcc}
\hline Symbol & Prefix & Multiple \\
\hline $\mathrm{T}$ & tera & $10^{12}$ \\
$\mathrm{G}$ & giga & $10^{9}$ \\
$\mathrm{M}$ & mega & $10^{6}$ \\
$\mathrm{k}$ & kilo & $10^{3}$ \\
$\mathrm{~m}$ & milli & $10^{-3}$ \\
\hline
\end{tabular}

\begin{tabular}{ccc}
\hline Symbol & Prefix & Multiple \\
\hline$\mu$ & micro & $10^{-6}$ \\
$\mathrm{n}$ & nano & $10^{-9}$ \\
$\mathrm{p}$ & pico & $10^{-12}$ \\
$\mathrm{f}$ & femto & $10^{-15}$ \\
$\mathrm{a}$ & atto & $10^{-18}$ \\
\hline
\end{tabular}


Useful physical constants

\begin{tabular}{lcc}
\hline Constant & Symbol & Value \\
\hline electron charge & $e$ & $-1.602 \times 10^{-19} \mathrm{C}$ \\
electron rest-mass & $m_{\mathrm{e}}$ & $9.109 \times 10^{-31} \mathrm{~kg}$ \\
proton rest-mass & $m_{\mathrm{p}}$ & $1.673 \times 10^{-27} \mathrm{~kg}$ \\
neutron rest-mass & $m_{\mathrm{n}}$ & $1.675 \times 10^{-27} \mathrm{~kg}$ \\
speed of e.m. waves in a vacuum & $c$ & $2.998 \times 10^{8} \mathrm{~m} / \mathrm{s}$ \\
permeability of free space & $\mu_{0}$ & $4 \pi \times 10^{-7} \mathrm{H} / \mathrm{m}$ \\
permittivity of free space & $\epsilon_{0}$ & $8.854 \times 10^{-12} \mathrm{~F} / \mathrm{m}$
\end{tabular}

Some Constants and Useful Information

base of natural logarithms $=e=2.71828$

The general relationship between numbers (or antilogarithms), bases and logarithms is

$$
\begin{array}{ll}
\text { number (antilogarithm) }= & \text { base }^{(\text {logarithm })} \\
\log _{10} \mathrm{e}=0.4343 & \log _{\mathrm{e}} 10=2.3026 \\
\log _{10} N=0.4343 \log _{\mathrm{e}} N & \log _{\mathrm{e}} N=2.3026 \log _{10} N
\end{array}
$$

Note: $\log _{10}$ is sometimes written as $\lg$ and $\log _{\mathrm{e}}$ is sometimes written as $\ln$ (= natural logarithm).

$$
\begin{aligned}
& \log _{a} m=\log _{b} m \times \log _{a} b=\log _{b} m / \log _{b} a \\
& \pi=3.14159 \\
& 360 \text { degrees }=2 \pi \text { radians } \\
& 1 \mathrm{rad}=360 / 2 \pi^{\circ}=57.2958^{\circ}=57^{\circ} 17^{\prime} 45^{\prime \prime} \\
& 1^{\circ}=0.01745 \mathrm{rad} \\
& 0 \mathrm{~K}=-273.15^{\circ} \mathrm{C} \\
& 273.15 \mathrm{~K}=0^{\circ} \mathrm{C}
\end{aligned}
$$

